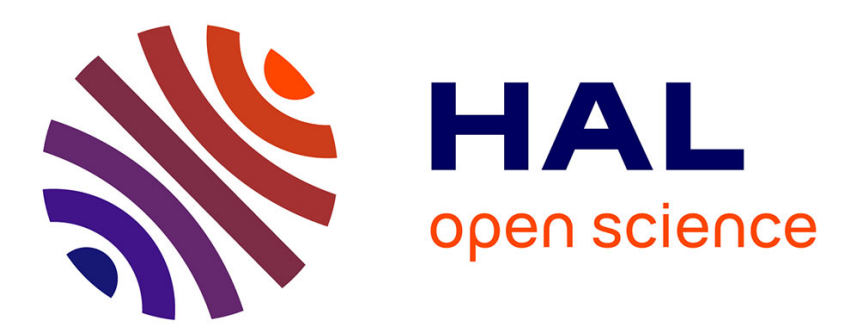

\title{
Dielectric study of SA1, SA2 and SÃ phases in liquid crystals of cyano compounds
}

C. Druon, J.M. Wacrenier, F. Hardouin, Nguyen Huu Tinh, H. Gasparoux

\section{To cite this version:}

C. Druon, J.M. Wacrenier, F. Hardouin, Nguyen Huu Tinh, H. Gasparoux. Dielectric study of SA1, SA2 and SÃ phases in liquid crystals of cyano compounds. Journal de Physique, 1983, 44 (10), pp.1195-1200. 10.1051/jphys:0198300440100119500 . jpa-00209703

\section{HAL Id: jpa-00209703 https://hal.science/jpa-00209703}

Submitted on 1 Jan 1983

HAL is a multi-disciplinary open access archive for the deposit and dissemination of scientific research documents, whether they are published or not. The documents may come from teaching and research institutions in France or abroad, or from public or private research centers.
L'archive ouverte pluridisciplinaire HAL, est destinée au dépôt et à la diffusion de documents scientifiques de niveau recherche, publiés ou non, émanant des établissements d'enseignement et de recherche français ou étrangers, des laboratoires publics ou privés. 


\title{
Dielectric study of $S_{\mathrm{A} 1}, S_{\mathrm{A}_{2}}$ and $S_{\tilde{\mathrm{A}}}$ phases in liquid crystals of cyano compounds
}

\author{
C. Druon, J. M. Wacrenier, F. Hardouin (*), Nguyen Huu Tinh $\left({ }^{*}\right)$ and H. Gasparoux $\left({ }^{*}\right)$ \\ Equipe « Nouveaux Matériaux » du Centre Hyperfréquences et Semiconducteurs (**), \\ U.E.R., I.E.E.A., Bâtiment P3 Université de Lille, 59655 Villeneuve d'Ascq Cedex, France
}

(Reçu le 23 décembre 1982, révisé le 13 juin 1983, accepté le 16 juin 1983)

\begin{abstract}
Résumé. - Les auteurs présentent une étude diélectrique des phases smectique $A$ monocouche $S_{A 1}$, bicouche $S_{A 2}$ et de l'antiphase $S_{\tilde{\mathbf{A}}}$ effectuée sur un mélange de 4-cyanobenzoyloxy-4'-pentyl stilbène (C5 stilbène) et de 4- $n$-hexylphényl-4'-cyanobenzoyloxy benzoate (DB6) ainsi que sur le DB6 pur.

Pour la direction de mesure $\mathbf{E} / / \mathbf{n}$ dans la phase $\mathbf{S}_{\mathbf{A} 2}$ les spectres diélectriques relevés montrent :

— une diminution de $\varepsilon_{\|}^{\prime}$

- une augmentation de l'énergie d'activation du mécanisme de réorientation moléculaire pour le DB6,

- l'apparition d'un deuxième domaine d'absorption pour le mélange lié soit à un phénomène coopératif, soit à l'existence de molécules de types différents.

Pour $\mathbf{E} \perp \mathbf{n}$, on note essentiellement une augmentation de $\varepsilon_{\perp}^{i}$ aux transitions $\mathrm{N}-\mathrm{S}_{\tilde{\mathbf{A}}}$ et $\mathrm{N}-\mathrm{S}_{\mathrm{A} 2}$.

Ces résultats semblent indiquer que de fortes corrélations dans le mouvement des molécules liées à de fortes interactions apparaissent surtout dans la phase $S_{A 2}$. Elles sont probablement dues, pour les produits que nous avons étudiés, à la présence dans la molécule de groupements ayant un moment dipolaire dont la composante transversale est importante.
\end{abstract}

\begin{abstract}
In this paper, the authors present a dielectric study of the monolayer $\left(\mathbf{S A}_{1}\right)$ and bilayer $\left(\mathbf{S A}_{2}\right)$ smectic phases and of the smectic antiphase $\left(\mathbf{S}_{\tilde{\mathbf{A}}}\right)$ for a mixture of 4-cyanobenzoyloxy-4'-pentyl stilbene (C5 stilbene for short) and 4-n-hexylphenyl-4'-cyanobenzoyloxy benzoate (DB6 for short) and for the pure compound DB6.

For the measurement with the direction of the electric field $\mathbf{E}$ parallel to the director $\mathbf{n}$, in the $\mathbf{S}_{\mathrm{A} 2}$ phase, the dielectric spectra observed reveal :

- a decrease of $\varepsilon_{\|}^{\prime}$,

- an increase of the activation energy of the molecular reorientation mechanism for DB6,

- the appearance of a second absorption domain for the mixture, connected either to a cooperative phenomenon or to the existence of molecules of different types.

For $\mathbf{E} \perp \mathbf{n}$, the study shows mainly an increase of $\varepsilon_{\perp}^{\prime}$ at the transitions $\mathrm{N}-\mathrm{S}_{\tilde{\mathrm{A}}}$ and $\mathrm{N}-\mathrm{S}_{\mathrm{A} 2}$.

These results suggest that there are strong correlations between the molecular motions, due to the presence of strong interactions, particularly in the $S_{\mathrm{A} 2}$ phase. These correlations are probably due, for the compounds studied, to the existence in the molecule of groups with dipolar moments whose transverse components are important.
\end{abstract}

\section{Introduction.}

It is well known that anisotropic phases of liquid crystals of cyano compounds can exhibit a large

(*) Centre de Recherche Paul-Pascal, Laboratoire associé au CNRS, 33405 Talence, France

(**) Laboratoire associé au CNRS, No 287. variety of structures. Thus, within the framework of uniaxial disordered smectic phases (or analogues), the following structures can be observed : smectic phases of monolayer type $\left(S_{\mathrm{A} 1}\right)$, partially bilayered $\left(\mathrm{S}_{\mathrm{Ad}}\right)$, bilayer $\left(\mathbf{S}_{\mathbf{A} 2}\right)$, antiphase $\left(\mathbf{S}_{\tilde{\mathbf{A}}}\right)$, and reentrant phases [1].

The $S_{A 1}$ phase is a smectic $A$ phase whose layer thickness is approximately equal to a molecular length $l[2]$. 
The $S_{\text {Ad }}$ phase has a layer thickness between $l$ and $2 l$ (typically $1.3 \mathrm{l}$ ). According to previous studies, this structure is due to a partial overlapping of the molecules [3].

In the $S_{A 2}$ phase the layer thickness is nearly $2 l$ (typically $1.9 \mathrm{l}$ ). There exist two commensurate periodicities : one with a wave length close to $l$, the other with a doubled wave length [2].

The $\mathbf{S}_{\tilde{\mathbf{A}}}$ phase is also a bilayer structure but with a modulation parallel to the layers [4]. This structure corresponds to a smectic $\mathrm{A}$ where the monolayer order is not perturbed, whereas the bilayer order goes from one preferential position to another in a direction parallel to the layers. Thus, as in the $S_{A_{2}}$ phase, there exist, along the director, two periodicities which are commensurate [5-6]. One corresponds to the molecucular length, the other to a molecular arrangement depending on the existence of dipoles in the molecule[7].

These structures have been revealed by using $\mathrm{X}$-rays and also by conducting physical and chemical studies (particularly microscopic and calorimetric observations) on pure compounds or binary mixtures.

At the present time, only a few results have been obtained by using the dielectric method to study these phases [8-9], except for the case of the structure $S_{\text {Ad }}[10-13]$.

In this paper, we present a characterization of the monolayer, bilayer and antiphase structures. To this end, we studied a mixture of $4 n$-hexylphenyl-4'-cyanobenzoyloxy benzoate (DB6) and 4-cyanobenzoyloxy 4'-pentyl stilbene (C5 stilbene) as well as pure DB6.

The formulae and transition temperatures (in ${ }^{\circ} \mathrm{C}$ ) of these compounds are as follows :

DB6 :

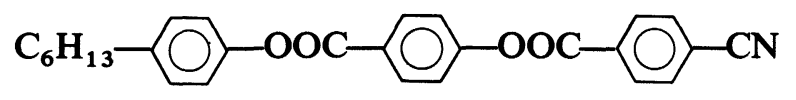

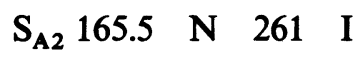

\section{C5 STILBENE :}

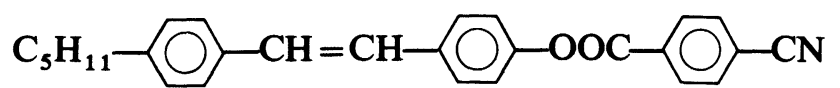

$$
\begin{array}{llllll}
S_{B} 137 & S_{A} 197 & N & 293 & I
\end{array}
$$

The mixture is constituted of $40 \%$ of DB6 and $60 \%$ of C 5 stilbene.

The phases obtained are :

$$
\begin{array}{lllllll}
\mathrm{S}_{\mathrm{A} 2} & 112 & \mathrm{~S}_{\tilde{\mathrm{A}}} & 126 & \mathrm{~S}_{\mathrm{A} 1} & 153 & \mathrm{~N}
\end{array}
$$

A study using X-rays has yielded some information about the structure of DB6 [14] and of a mixture rather similar to the one used by us : C5 stilbene and DB5 (54\%) [4]. This study showed the existence of phases $S_{\mathbf{A} 1}, S_{\mathbf{A} 2}$ and $S_{\tilde{A}}$ for the mixture.
Since the configuration of these phases partly comes from dipolar interactions between molecules, the dielectric study should yield useful information about these structures, particularly about the dynamics of the molecular motions.

When the electric field $\mathbf{E}$ is parallel to the director $\mathbf{n}$, the reorientation mechanism of the component of dipole moment parallel to the molecular axis $L$ is revealed. On the other hand, for $\mathbf{E} \perp \mathbf{n}$, the librational or rotational movements of the component of the dipole moment perpendicular to $L$ are observed. By performing this study at various temperatures, the activation energy of these various mechanisms can be deduced [15-16].

\section{Experimental.}

The study of the complex permittivity $\varepsilon^{*}=\varepsilon^{\prime}-j \varepsilon^{\prime \prime}$ is performed within a wide frequency band $(1 \mathrm{~Hz}-$ $1 \mathrm{GHz}$ ). The measurement cell is a capacitor located at the end of a coaxial line [17]. Depending on the frequency band, various measurement devices are used [18]. The molecules in the nematic phase are orientated by means of a magnetic field of $11 \mathrm{kG}$. The alignment in the smectic phase is achieved by a slow decrease of the temperature, the sample remaining in the magnetic field.

The accuracy of the results obtained is $2 \%$ for $\varepsilon^{\prime}$ and $5 \%$ for $\varepsilon^{\prime \prime}$. The temperature of the sample remains stable to within $0.2{ }^{\circ} \mathrm{C}$ thanks to a thermal regulation device.

Thus, our cell allows us to study the mixture and DB6 but the transition temperatures of C5 stilbene are too high.

\section{Experimental results.}

3.1 Static Permitrivity. - The study of the static permittivity is performed at low frequency $F_{\mathrm{s}}$. This frequency is selected so as to remain, at the measurement temperature, lower than frequencies of absorption domains and higher than frequencies of the conductivity mechanism.

Figures 1 and 2 show the results obtained for DB6 and for the mixture.

For both cases, a strong decrease of $\varepsilon_{\|}^{\prime}$ with decreasing temperature can be noticed. This behaviour

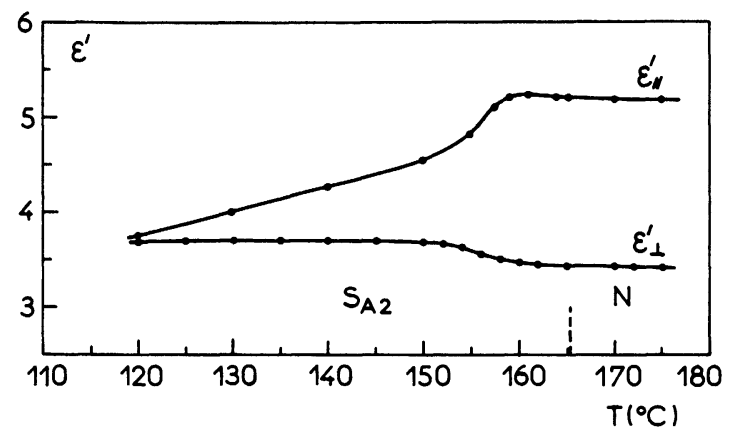

Fig. 1. - Quasi-static permittivity for DB6. 


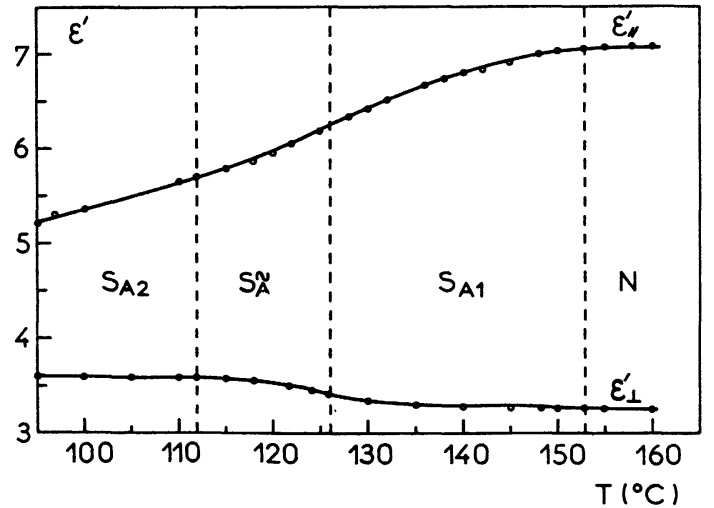

Fig. 2. - Quasi-static permittivity for the mixture : DB6 in C5 stilbene.

is particularly striking in the $\mathrm{S}_{\mathrm{A} 2}$ phase of DB6 $\left({ }^{1}\right)$. This feature was originally discovered by $L$. Benguigui and F. Hardouin [9]. On the other hand, an increase of $\varepsilon_{\perp}^{\prime}$ is observed in the following cases :

- at the transition $\mathrm{N}-\mathrm{S}_{\mathrm{A} 2}$ for DB6

- at the transition $S_{\mathrm{A} 1}-S_{\tilde{A}}$ for the mixture.

\subsection{DYNAMIC PERMITTIVITY.}

3.2.1 E/n. $-a)$ DB6. When the electric field $\mathbf{E}$ is parallel to the director $n$, the absorption diagram obtained for the nematic and $S_{A 2}$ phases is a half circle centred on the abscissa axis (Fig. 3 at $T=150^{\circ} \mathrm{C}$ and $T=120^{\circ} \mathrm{C}$ ). Therefore, this mechanism is of a Debye type. The amplitude of this domain strongly decreases when the temperature decreases in the $\mathrm{S}_{\mathrm{A} 2}$ phase.

b) Mixture. For the nematic and $\mathrm{S}_{\mathrm{A} 1}$ phases, the diagram obtained is also of a Debye type (Fig. 4 at $T=158^{\circ} \mathrm{C}$ and $\left.T=150^{\circ} \mathrm{C}\right)$. However, when the temperature decreases, going rom the $S_{\tilde{A}}$ phase to the $\mathrm{S}_{\mathrm{A} 2}$ phase, the diagram shows a distortion increasing with the decrease of temperature (Fig. 4).

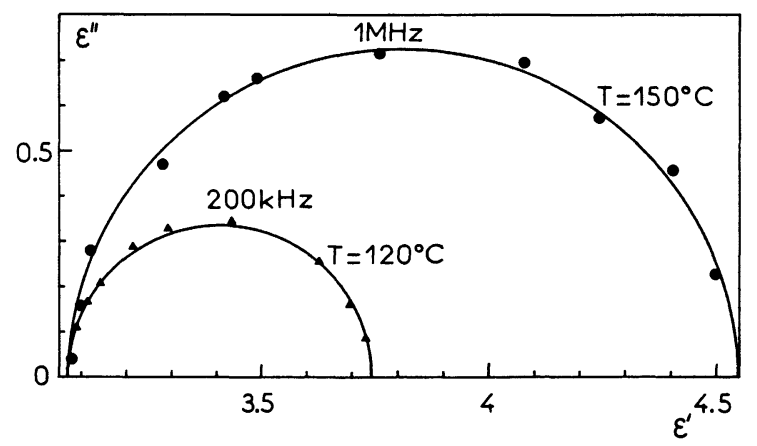

Fig. 3. - Cole and Cole diagram obtained for $\mathrm{E} / / \mathbf{n}$ for DB6.

( $\left.{ }^{1}\right)$ During the experiment, the sample of DB6 changed slightly, resulting in a decrease of the transition temperature $\mathrm{N}-\mathrm{S}_{\mathrm{A2}}$. In figure 1, the decrease of $\varepsilon_{\|}^{\prime}$ revealed around $157^{\circ} \mathrm{C}$ corresponds to the transition temperature of the sample in our experiment.

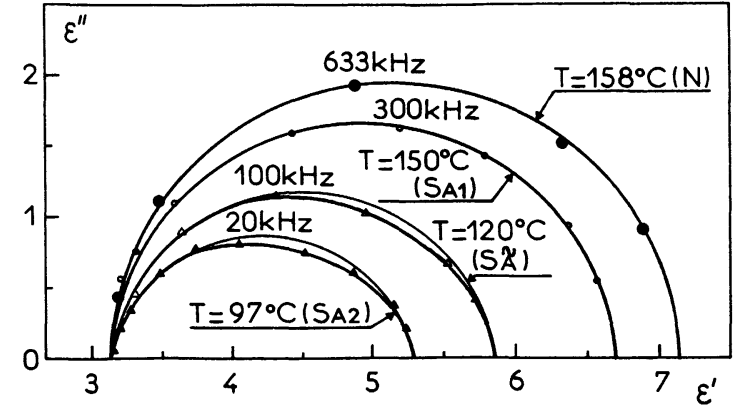

Fig. 4. - Cole and Cole diagram obtained for $\mathbf{E} / / \mathbf{n}$ for the mixture at different temperatures.

If this distortion is assumed to be the result of a Cole and Cole distribution of relaxation times [19], the value of the characterizing parameter $\alpha$ can be deduced. In the relaxation equation this parameter appears as follows :

$$
\varepsilon^{\prime}=\varepsilon_{\infty}+\frac{\varepsilon_{\mathrm{s}}-\varepsilon_{\infty}}{1+\left(i \omega \tau_{0}\right)^{1-\alpha}}
$$

when there is no distribution, $\alpha=0$ and the wider the distribution the larger this parameter is (Fig. 5).

We obtain :

Table I. - Distribution parameter $\alpha$ versus temperature.

\begin{tabular}{|c|c|c|c|c|}
\hline$T^{\circ} \mathrm{C}$ & $158(\mathrm{~N})$ & $150\left(\mathrm{~S}_{\mathrm{A} 1}\right)$ & $120\left(\mathrm{~S}_{\mathrm{A}}\right)$ & $97\left(\mathrm{~S}_{\mathrm{A} 2}\right)$ \\
\hline$\alpha$ & 0.021 & 0.041 & 0.09 & 0.14 \\
\hline
\end{tabular}

However, it may be noticed that for $\mathbf{S}_{\tilde{\mathbf{A}}}$ phases and particularly $S_{A 2}$ phases, the domain observed differs from the Cole and Cole distribution. So, to interpret the shape of the absorption obtained, we applied a numerical decomposition method to the distributed domain [20]. This study was carried out for the domain at $T=97^{\circ} \mathrm{C}$ (Fig. 6). The results show that this domain is the superposition of two domains of the Debye type with the following characteristics :

- domain I : $F_{\mathrm{cI}}=4.56 \mathrm{kHz}$,

$$
\text { amplitude } A_{\mathrm{I}}=0.686
$$

— domain II : $F_{\text {cII }}=24.2 \mathrm{kHz}$, amplitude $A_{\mathrm{II}}=1.414$

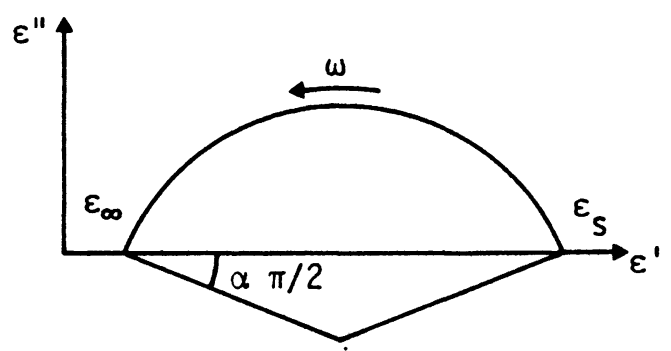

Fig. 5. - Cole and Cole diagram. 


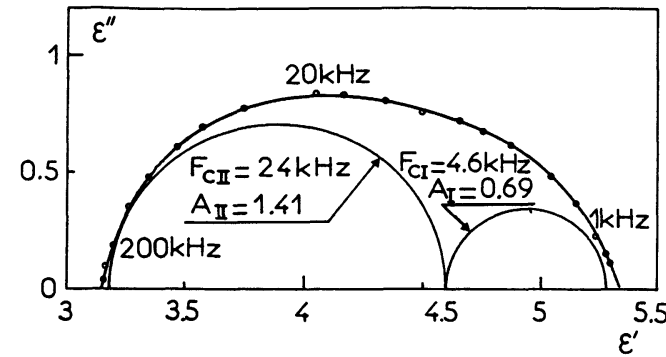

Fig. 6. - Absorption domain obtained for $\mathbf{E} / / \mathbf{n}$ for the mixture at $T=97^{\circ} \mathrm{C}$.

It can be deduced that in $\mathrm{S}_{\tilde{\mathbf{A}}}$ phase, an additional domain appears with a critical frequency lower than that of the main domain. Its amplitude increases with decreasing temperature and becomes higher at low temperature in the $S_{A 2}$ phase.

3.2.2 $\mathrm{E} \perp \mathrm{n}$. - When the electric field is perpendicular to the director, a distributed relaxation domain located in a higher frequency band can be observed. Figure 7 shows a spectrum $\varepsilon^{\prime \prime}=f(F)$ obtained for the mixture at $T=100^{\circ} \mathrm{C}$. No measurements for frequencies higher than $1 \mathrm{GHz}$ could be obtained because devices working within the $1 \mathrm{GHz}-30 \mathrm{GHz}$ range necessitate a larger sample than the one we had. The interpretation of this type of spectrum is difficult because numerous mechanisms are involved. The absorption observed is a characteristic of the librational and rotational motions of the molecules and of the intramolecular movements [12].

3.2.3 Investigation at various temperatures. a) DB6. Figure 8 shows the variation of the critical frequency of the domain observed for $\mathbf{E} / / \mathbf{n}$ versus the measurement temperature. The diagram obtained is made up of straight lines. Using Arrhenius law for each phase :

$$
F_{\mathrm{c}}=F_{0} \mathrm{e}^{-\boldsymbol{W} / \boldsymbol{k} T} .
$$

We can deduce the activation energy $W$ of the mechanism.

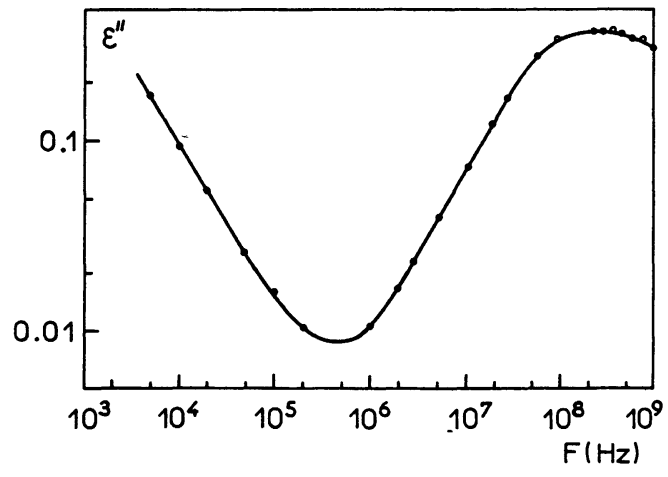

Fig. 7. - Evolution of $\varepsilon_{\perp}^{\prime \prime}$ versus frequency for $\mathbf{E} \perp \mathbf{n}$ for the mixture at $T=100^{\circ} \mathrm{C}$.

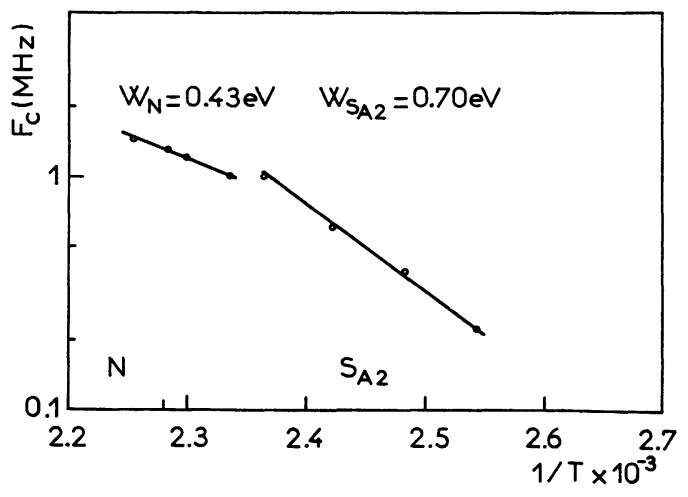

Fig. 8. - Evolution of $F_{\mathrm{c}}$ versus $1 / T$ for DB6.

We obtain :

$$
\begin{aligned}
W_{\mathrm{N}} & =0.43 \mathrm{eV} \\
W_{\mathrm{SA} 2} & =0.70 \mathrm{eV} .
\end{aligned}
$$

An important variation of the activation energy at the transition $\mathrm{N}-\mathrm{S}_{\mathrm{A} 2}$ can be noticed.

b) Mixture. Figure 9 gives the results obtained for the mixture. In the various phases we obtain :

$$
\begin{aligned}
W_{\mathrm{N}} & =0.75 \mathrm{eV} \\
W_{\text {SA1 }} & =0.75 \mathrm{eV} \\
W_{\text {S̃ }} & =0.72 \mathrm{eV} \\
W_{\text {SA2 }} & \sim 0.9 \mathrm{eV} .
\end{aligned}
$$

For the $\mathrm{S}_{\mathrm{A} 2}$ phase, the domain being distributed, the apparent frequency of the distributed relaxation domain is reported. In this case, the diagram obtained is not very accurate and the results are only qualitative.

\section{Interpretation of the result obtained for $E / / n$.}

4.1 DB6. - In $\mathrm{N}$ and $\mathrm{S}_{\mathrm{A} 2}$ phase of $\mathrm{DB6}$, a single relaxation domain of the Debye type is observed. Therefore, this domain is characteristic of a single molecular mechanism which can be attributed to the

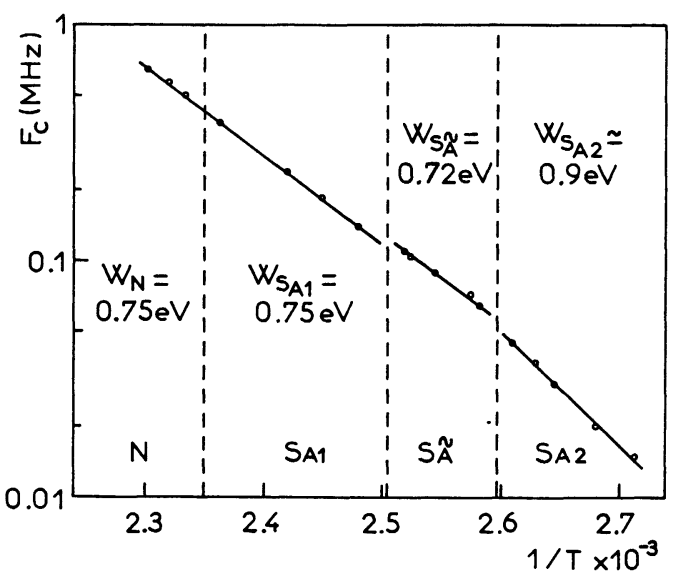

Fig. 9. - Evolution of $F_{\mathrm{c}}$ versus $1 / T$ for the mixture. 
reorientation motion of the molecules around an axis perpendicular to their longitudinal axis [21-22]. In fact, the values of the critical frequencies obtained in the $\mathrm{N}$ phase (about $1 \mathrm{MHz}$ ) and the corresponding activation energy $(0.43 \mathrm{eV})$ agree with the values obtained for other compounds [23-24].

The increase of activation energy in the $S_{\mathrm{A} 2}$ phase characterizes an increase of the energy required for the reorientation motion of the molecules. This increase can be due to extra interactions occurring in this phase and related to the existence of two polar groups with a strong component perpendicular to the longitudinal axis of the molecules. In this respect De Jeu has shown that in the smectic phase of some compounds, such lateral dipolar components can interact strongly [25].

The increase of $\varepsilon_{\perp}^{\prime}$ at the transition $\mathrm{N}-\mathrm{S}_{\mathrm{A} 2}$ can also be explained by these extra interactions and shows that the latter are of a ferro-electric type.

4.2 MixtuRE. - For the mixture, in $\mathrm{N}$ and $\mathrm{S}_{\mathrm{A1}}$ phases, a domain of the Debye type can be observed. As for the DB6, it can be attributed to the reorientational motion of the molecules. The critical frequencies obtained (from $100 \mathrm{kHz}$ to $700 \mathrm{kHz}$ ) are quite characteristic of this motion.

In the $\mathbf{S}_{\tilde{\mathbf{A}}}$ phase, this domain shows a shape whose distribution increases with decreasing temperature. In the $\mathrm{S}_{\mathrm{A} 2}$ phase, this distribution can be broken up into two domains. The appearance of this second domain can be explained in two ways.

The first explanation is based on the results of a theory recently proposed by L. Benguigui [26]. In this theory, the author studies the dielectric properties of $S_{A 1}, S_{A 2}, S_{\tilde{A}}$ phases applying the formalism of Landau's theory for phase transitions. The author predicts the existence of a single relaxation mode in the $\mathrm{S}_{\mathrm{A} 1}$ phase and of two modes in the $\mathrm{S}_{\tilde{\mathrm{A}}}$ and $\mathrm{S}_{\mathrm{A} 2}$ phases.
Therefore, the supplementary domain we have observed would be related to the collective phenomena described in this theory. However, it is to be noted that we did not observe this second mode in the spectrum of DB6, perhaps because, in this case, its amplitude is too low to be observed.

The second explanation is based on the fact that we observed the supplementary domain only for the mixture. The DB6 molecule has two transverse dipolar moments due to $\mathrm{COO}$ groups whereas the C5 stilbene molecule has only one. Thus, in the $S_{\tilde{A}}$ and $S_{A 2}$ phases, the interactions of these two molecules with their surroundings are different, though these surroundings are similar because of mass diffusion processes. Therefore, the reorientation motion of one of them can be easier than for the other.

As the experimental study has been performed on only two compounds, it is difficult to choose between the two explanations suggested. Further investigations on other compounds with these phases seem to be necessary.

The activation energy measurements for the mixture show that this energy does not change for the transitions $\mathrm{N}-\mathrm{S}_{\mathrm{A} 1}$ and $\mathrm{S}_{\mathrm{A1}}-\mathrm{S}_{\tilde{\mathrm{A}}}$. The value obtained $(0.75 \mathrm{eV})$ is higher than that obtained for DB6 but remains of the same order of magnitude as those obtained in $\mathbf{N}$ phase for other compounds [11, 24, 27]. The study of the activation energy in the $\mathrm{S}_{\mathrm{A} 2}$ phase is more difficult because of the superposition of the two domains. The variation of apparent critical frequency seems to show that at least one of the domains has a more important energy than in other phases. This increase can be explained by a mechanism similar to the one proposed for DB6.

\section{Acknowledgements.}

We wish to thank Dr. L. Benguigui and J. Prost for valuable discussions.
[1] Hardouin, F. and Levelut, A. M., J. Physique 41 (1980) 41 .

[2] Hardouin, F., Levelut, A. M., Benattar, J. J., Sigaud, G., Solid. State Commun. 33 (1980) 337.

[3] Leadbetter, A. J., Frost, J. C., Gaughan, J. P., Gray, G. W., Mosley, A., J. Physique 40 (1979) 375.

[4] Sigaud, G., Hardouin, F., Achard, M. F., Levelut, A. M., J. Physique 42 (1981) 107.

[5] Prost, J., Proceedings of the liquid crystals of one and two dimensional order conference, Garmish-Partenkirchen (1980), Springer series in chemical physics (Springer, Berlin, Heidelberg, New York) 1980.

[6] Prost, J., J. Physique 40 (1979) 581.

[7] Hardouin, F., Sigaud, G., Nguyen HuU Tinh, ACHARD, M. F., J. Physique Lett. 42 (1981) L-63.
[8] Benguigui, L., Hardouin, F., J. Physique Lett. 42 (1981) L-111.

[9] Benguigui, L., Hardouin, F., J. Physique Lett. 42 (1981) L-381.

[10] Druon, C. and Wacrenier, J. M., J. Physique 38 (1977) 47.

[11] Druon, C., Wacrenier, J. M., Ann. Phys. 3 (1978) 199.

[12] Druon, C., WaCrenier, J. M., Mol. Cryst. Liq. Cryst. 88 (1982) 99.

[13] Bata, L., Buka, A., Acta Physica Polonica A 545 (1978) 635.

[14] Hardouin, F., Levelut, A. M., Sigaud, G., J. Physique 42 (1981) 71.

[15] WaCrenier, J. M., Druon, C., Lippens, D., Mol. Phys. 43, 1 (1981) 97.

[16] Levelut, A. M., Druon, C., J. Physique Lett. 43 (1982) L-193. 
[17] Druon, C., Wacrenier, J. M., J. Phys. E 16 (1983) 151.

[18] Benadda, M. D., Carru, J. C., Druon, C., J. Phys. E. 15 (1982) 132.

[19] Cole, K. S., Cole, R. H., J. Chem. Phys. 9 (1941) 341.

[20] Chapoton, A., Ravalitera, G., Choquet, M., VanDORPe, B., Gengembre, L., Revue Phys. Appl. 10 (1975) 153.

[21] Martin, A. J., Meier, G., Saupe, A., Symp. Faraday Soc. 5 (1971) 119.

[22] Nordio, P. L., Rigatti, G. and Segre, U., Molec. Phys. 25 (1973) 129.
[23] Parneix, J. P., Chapoton, A., Mol. Cryst. Liq. Cryst. $78(1-4)(1981) 115$.

[24] Bata, L., Buka, A., Molnar, Mol. Cryst. Liq. Cryst. 38 (1977) 155.

[25] De Jeu, W. H., Goossens, W. J. A., Bordewijk, P., J. Chem. Phys. 615 (1974) 1985.

[26] Benguigui, L., J. Physique 44 (1983) 273.

[27] Galerne, Y., C.R. Hebd. Séan. Acad. Sci. B 278 (1974) 347. 